\title{
A Problem-Based Learning Approach Enhancing Students' Awareness of Natural Risks and Hazards in Italian Schools
}

\author{
Susanna Occhipinti \\ Technical High School Innocent Manzetti, 11100 Aosta, Italy; susocchip@gmail.com
}

Received: 28 May 2019; Accepted: 21 June 2019; Published: 26 June 2019

\begin{abstract}
The goal of the present research is to contribute to spreading in Italian schools greater awareness of the dangers derived from natural phenomena, such as landslides, floods or earthquakes. The essential steps are: developing the understanding of the territory's inevitable evolution (derived from natural geological phenomena that normally concern it); raising the awareness of dynamics regarding the territory in which one lives (through geological and historical analysis of the context); and finally recognizing the speed and frequency with which different natural phenomena occur, and the surface they might affect. Thereafter, the research's next step is gaining the awareness that these phenomena may become actual risks and cause damage, in relation to the territory's use and vulnerability. Finally, its last step is realizing that knowledge on such dynamics is needed for risk-prevention and reduction in vulnerable contexts. In fact, it seems that, until these natural manifestations remain far from students' everyday lives, they are not adequately acknowledged. Moreover, since it has been proven that the usual transmissive approach to the subject is not effective, a problem-based learning approach was experimented. The path was defined through disciplinary objectives and through developing and monitoring specific skills. During experimentation, investigative and practical activities showed an interesting growth of the involved students' skills and competences. The research's double aim of raising greater awareness of environmental dynamics and risks, and of developing greater technical skills and sense of citizenship among students (also concerning the observation and recognition of relationships) seems to have been achieved.
\end{abstract}

Keywords: problem-based learning; educational approach; natural risks and hazards

\section{Introduction}

A certain lack of awareness of natural hazards can be accepted and tolerated in a country where these hazards are occasional, predictable and circumscribed, but Italy is one of the most sensitive countries as to all types of risk: geological, hydrogeological, volcanic and seismic. This because of its geological nature and geomorphological evolution, of the high energy of its relief, and of the torrential flow of its rivers, but most of all, it is because of the intensive exploitation of its territory, a lack of careful territorial planning, and an inadequately diffused (and that has to be rethought) environmental, scientific and geological culture.

In Italian society, the issues of Earth Science, notably the focus on natural risks and hazards, are definitely not emphasized enough. Furthermore, they are poorly disseminated, both in schools, among students of all ages, and in the social community. The logical consequence is the lack of attention towards our fragile landscape and our architectural heritage of great historical value, and also an extraordinarily high frequency of natural disasters, with consequent casualties and damage to buildings and infrastructures. 
This lack of awareness, in a fragile country as Italy, has unavoidable effects on the buildings' safety, on the economy, on environmental protection, and ultimately on the quality of life. Too often we become aware of dangers too late, when damage to people and material things has already occurred: this, even in presence of vulnerable assets and risks that are close to daily life.

\section{The Role of Education}

The role of education, at all levels, can be fundamental in growing among younger generations an environmental geological culture and greater awareness of natural hazards and risks. The aim is to draw greater attention on our own territory, for the development of a stronger "sense of belonging" to this environment of great naturalistic and cultural value.

Earth Science is taught in all schools and at all ages, with different levels of depth and quality of teaching. Plate tectonics and natural hazards (such as volcanoes or earthquakes) are curricular topics in school, but, on the other hand, communities that live on volcanoes' sides or in seismic areas do not perceive dangers and risks, even when these areas have already been affected by disastrous events in recent past: human memory is very short.

Many studies [1-5] have highlighted the poor skills of Italian students in the Earth Science field, both during and at the end of their cycle of studies, regardless of the subject's curriculum or of their level of scientific specialization. Their knowledge is often superficial and fragmentary, due to the compulsory compliance to ministerial curricula, which even today, and even in scientific courses of study, do not include neither Natural Science nor Earth Science in the final exam's written tests.

Inadequate knowledge does not allow the acquisition of effective and essential skills: this, also because of a curriculum that, even if renewed in recent years, remains fragmentary, devoid of prerequisites and without coordination with other scientific disciplines, such as Physics, Chemistry and Biology, all taught by the same teacher.

The school years' dynamics determine the choice of university and the scarce participation in Earth Science Olympiads (in relation to the other scientific disciplines' ones). In students, now totally relying on Google apps, we note the scarce ability to use maps or to read the surrounding landscape.

This type of content's teaching-learning process has great responsibilities: in fact, even when proposed by trained and motivated teachers, it fails to reach the students. It equips them with theoretical knowledge, but not with the necessary awareness and consciousness.

The causes may be different. For example, the teachers' limited competence in the Earth Science field: mainly biologists, in Italian schools they must teach both subjects, as requested by Natural Science's curriculum. Minor knowledge of the discipline leads to minor proficiency in it, and often to less passion for it: a discipline that seems, at first sight, arid, studying rocks and minerals, volcanoes and earthquakes, floods and landslides. Furthermore, in Earth Sciences it may seem difficult to carry out practical laboratory activities, and this makes the subject less exciting for students. Finally, its nature of still young and fragmented discipline, lacking in epistemology, may make its teaching-learning process less attractive.

\section{The Research}

The goal of the present research, recently developed but already tested in several classes, is to contribute to spreading in Italian schools greater awareness of dangers derived from natural phenomena. In fact, although dangers associated with the territory's geological dynamics have long been included in all ministerial curricula and are frequently addressed by science teachers, such awareness of the derived risks is still to be developed.

The result is a widespread form of unconsciousness, of lack of interest in environmental issues such as the exploitation of one's own territory, with little respect for the beautiful environmental, natural and architectural assets that characterize the Bel Paese. Real knowledge must instead be consolidated, to the point of diffusing the awareness that these phenomena (landslides, earthquakes or volcanic eruptions) are common, cyclical, unavoidable events that are part of our history and, sometimes, of our lives. 
The different necessary steps to achieve the goal develop through the understanding of the territory's inevitable evolution (derived from natural geological phenomena that normally concern it); and through the recognition of the speed and frequency with which these phenomena occur, and of the surface they might affect. Moreover, students must become aware that these phenomena, in relation to the territory's exploitation and its consequent vulnerability, may become actual risks and cause damage. Finally, they must understand that their knowledge is needed, for the purposes of risk-prevention and reduction in vulnerable contexts.

The choice was therefore to start from a familiar and local context, in order to extend this type of knowledge and awareness towards complex, distant and global phenomena. In fact, it seems that, until these natural manifestations remain far from students' everyday lives, they are not adequately acknowledged.

\section{The Educational Approach}

Since it has been shown that the usual transmissive approach to the subject is not proving effective, a Problem-Based Learning approach (hereinafter called PBL) was tried. This type of approach had already been tested by the author in previous studies [1,2], where it proved to be particularly effective, applicable and flexible. From my experience, in fact, PBL is not characterized by the rigidities we find in other methodological approaches, such as Inquiry-Based Science Education (IBSE). Other types of approach were tested: the traditional "application of experimental protocols" is generally easier, but less effective and less fun; "formulating and testing hypotheses" is more complex and formative, but the students' involvement depends on the subject or on the question, the "hands-on experimentation" approach is undoubtedly the most popular, although it carries the risk of being a little playful and not so rigorous.

PBL is, more precisely, generally based on an abductive approach. The process is aimed at using the power of authentic problem solving to engage students and enhance their learning skills and motivation. It develops critical thought and creative skills, and it improves problem solving skills, with the aim of making students apply their knowledge to new situations.

Having to cope with in-context situations and appropriately structured problems, students are asked to investigate and discover meaningful solutions.

Indeed, this approach is rich in meaning and potential outcomes, but it requires commitment, time and passion. Moreover, obviously, even if it cannot completely replace standard lessons, it is important not to confuse PBL with simple practical activities included in the traditional education system, enacted only to vary the type of communication or as the culminating events of single training units. However, PBL poses certain challenges to teachers. Their role changes significantly as they become facilitators of learning, that promote a setting of inquiry rather than providing facts and then testing the students' ability to recall them through memorization. Furthermore, they lose their role of conductors of lessons, of transmitters of culture, of people who hold power in classrooms: they need to be open to a constructivist attitude, and to be able to adopt a student-centered approach [1-5].

To help teachers, Thomas et al. [6] proposed some useful criteria for structuring problems, cases and situations whose solution may require a PBL approach. These criteria describe how:

(1) projects should focus on problems that push students to think about major concepts;

(2) these projects should engage students in constructivist investigations, making them work as autonomous active investigators and problem-solvers;

(3) problems/cases should be related to specific contexts;

(4) learning should be driven by challenging, open-ended problems with no set answer.

Rigorous, meaningful and effective Project-Based Learning requires:

- critical thought, problem solving skills, collaboration and various forms of communication;

- inquiry as part of the learning and creative process (creation of ideas, projects, interpretations); 
- an open-ended Driving Question, that should force students to exchange views and interact, by facing challenges and problems.

A standard question is generally based on the fundamental questions "What?", "Why?" and "Where?". This process gives teachers a quick scan of the students' knowledge, is based on facts and has only one correct answer. On the other hand, an open-ended question is based on concepts or ideas, and it requires pupils to carry out researches, to investigate and reflect before answering: it should be provocative and challenging, precisely because it is matter of interest. It has no set answer, but it stimulates the formulation of hypotheses, opinions, concepts or ideas. PBL begins with the introduction of context-related problems, and needs to be developed while progressively engaging in problem solving. During PBL activities, a great amount of time is spent in discussing problems, in making hypotheses, in identifying relevant facts, in gathering information and in defining learning issues. With this approach, the Driving Question, in response to which the learning path is defined, becomes the basic tool: it simply has to be stated, so that students can understand its true content and solve problems by themselves; it should engage them and raise their interest and curiosity; as commonly used, it should drive them to "uncover the standards" [2].

To formulate a good Driving Question, a realistic problem-based scenario must be established. Afterwards, the actual question has to be formulated, question that, focusing and driving the project, should not be easily answered to. Instead, it should be useful to students in formulating new questions, answerable (not through an easy process) but manageable, recalling on students' previous knowledge: it should help them apply their learning to new situations, and integrate standards from a variety of disciplines; finally, it should encourage them to make connections between disciplines and produce multiple approaches to problem solving.

PBL seems to be more easily applicable to Earth Sciences than other approaches: it is more dynamic and effective, allowing to face problems, to solve them or at least to search for solutions. It requires students to research, investigate, reflect and reorganize their knowledge in innovative, meaningful ways.

Different educational approaches to the same subject were proposed and experimented with students, to demonstrate how different approaches to the same activity, variously structured, may generate significantly different results in the phenomenon's perception and understanding. (Table 1).

Table 1. Examples of open questions regarding the same subject, formulated with different educational approaches [2].

\begin{tabular}{|c|c|c|}
\hline Approach & Model & Question \\
\hline Deductive & Formal scientific protocol & What happens if you change the slope gradient? \\
\hline Inductive & Analysis of variables to obtain a rule & $\begin{array}{l}\text { What factors may vary and cause the fall of a } \\
\text { landslide? }\end{array}$ \\
\hline Abductive & PBL-case analysis-back analysis & $\begin{array}{l}\text { A landslide fell. What may have been the event's } \\
\text { cause in the present context? }\end{array}$ \\
\hline
\end{tabular}

\section{The Educational Path}

The research's target, which will be further extended, were secondary school students. The employed path was defined through disciplinary and transversal objectives and specific skills to be developed and monitored. After their application, investigative and practical activities actually showed an interesting growth of skills and competences among the involved students.

This path, structured through different activities and tools, allowed experimentation on various approaches towards active teaching-learning, with respect to natural hazards and risks. The objective was to generate among students an effective approach in understanding these risks. The aims were: to recognize a phenomenon; to evaluate how it may evolve if its basic parameters change; to understand risks; and to relate them with human impact on the environment. The knowledge of the different 
meanings of hazard, risk and vulnerability can be theoretical, or derived from case analysis, therefore direct, practical and perhaps more effective.

The intention, while planning and structuring the educational path's activities, was to find "general laws", historically and scientifically based:

- a phenomenon that occurred in the past needs to be studied, also because, according to actualism/uniformitarianism, it may happen again;

- it is possible to recognize recurrent characteristics in phenomena (lithologies, material geometries, slopes, physical or chemical parameters and anthropic action), that circumscribe the areas in which these phenomena may occur;

- $\quad$ each phenomenon must be considered as a complex system;

- it is possible to consider the time factor, which has regularities;

- finally, these principles can be applied in precise, familiar or at least known contexts: they can succeed in generalizing phenomena, in formulating other principles and in abstracting the concepts of danger and, perhaps, risk.

The educational path has several steps. Students must, in fact:

(1) know, in their main points, the territory's dynamics and the associated dangers, such as landslides, avalanches, floods, earthquakes etcetera;

(2) verify, possibly through experimentation, under what conditions these natural manifestations occur, what are their triggering factors, their stability limits and the probability of their occurrence;

(3) recognize, in their own environment or in known areas, the existence of different phenomena,

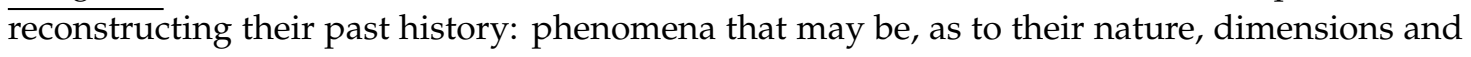
consequences, potentially dangerous, and, in different aspects, concerning their own lives;

(4) become aware of the instability of their environment, identifying through experimentation the potentially involved areas and infrastructures, thus passing from the concept of danger to that of vulnerability and therefore of risk;

(5) hypothesize instruments of protection and constraint, without excluding the zero option, which is relocation.

Each step requires adequate Driving Questions and tools, to make the research for effective answers, solutions or new hypotheses and Driving Questions more operative.

For obvious reasons, only appropriate examples of tools and Driving Questions will be presented, in order to solicit discussion and analysis among students and develop the research's path.

The definition of the educational path required some working time, in which students were free (even if properly guided) to discuss among themselves in groups, looking for useful materials and documents.

\section{The Choice of Focus}

The territory in which the experience takes place obviously directs the educational path's choice. In our case, the activity took place and was experimented in schools located in a mountainous region, with high slope energy, rapid evolutionary dynamics and frequent interactions with the anthropized territory. These conditions have inevitably determined landslide phenomena to be chosen as a focus, but the present didactic methods and educational choices are applicable to other contexts and to any type of danger.

\section{The Choice of Tools}

The choice of teaching tools took into account their availability. If it is true that computer tools, generally easily accessible and inexpensive for teaching, allow students to experiment with virtually all sorts of phenomena, and adapt to their current way of thinking and attitudes, on the other hand 
they seem poorly effective for the purposes of understanding, memorization and of course for a full immersion in phenomena.

On the contrary, the proposed tools, that may seem crude and trivial, obtain the result of making a phenomenon understood in its variables: then, they stimulate its memorization, and, last but not less important, they make students appreciate and enjoy the activities, which is the first step to get passionate about a subject.

The objective is to recognize, through very simple models and practical activities, the classification of landslides. The most widely known and used is Varnes' (Figure 1) normally presented in textbooks through graphic representations and the corresponding photographs of various phenomena: these are memorized by students, that however do not seem able to translate the images or the patterns into practical knowledge and application skills in real cases.
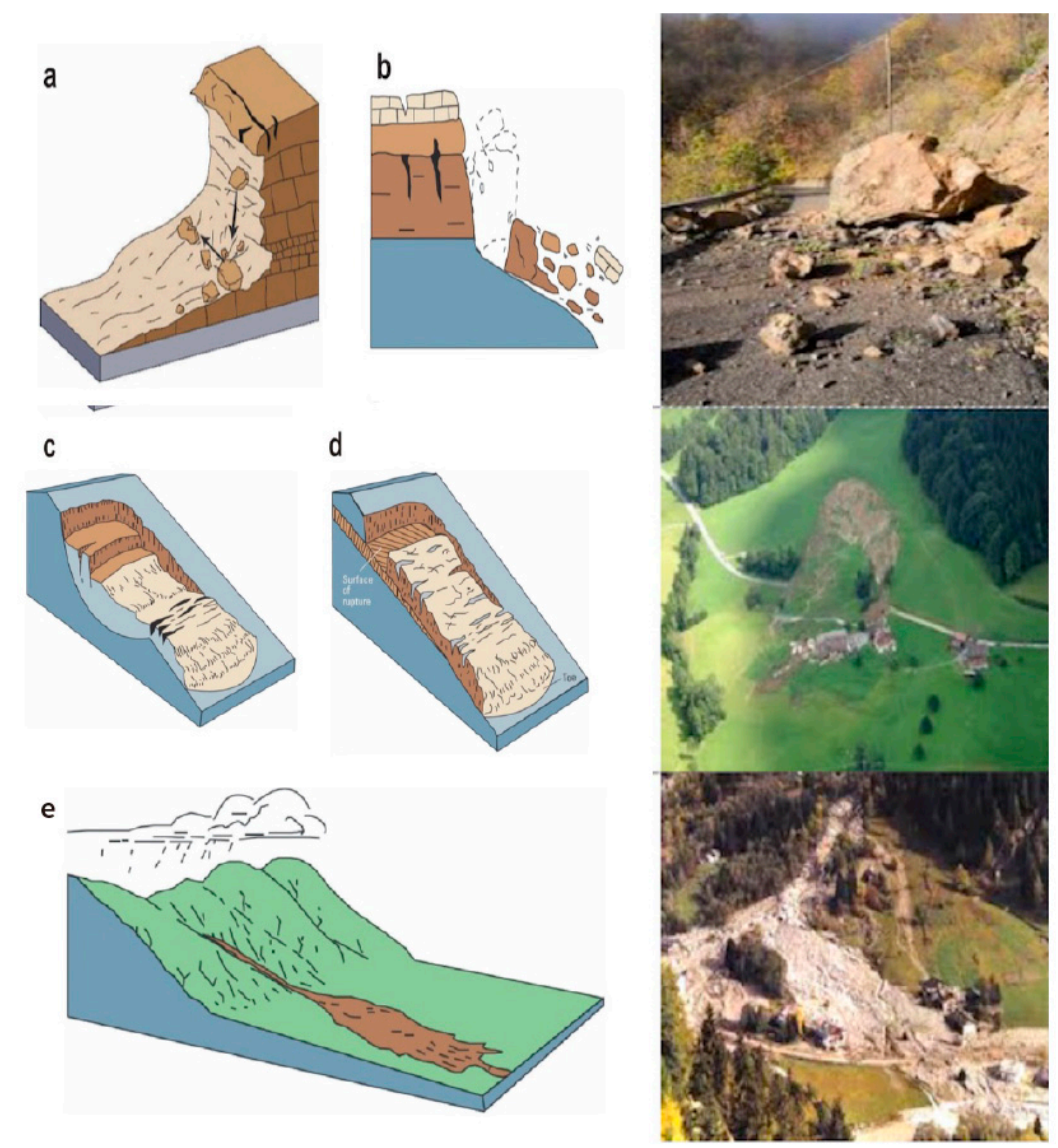

Figure 1. Varnes' classification with examples, from a textbook.

Students can, through using models, really understand a phenomenon, directly experience it, modify its factors and parameters and easily measure its verifiable variables, which are: the materials, its size and coherence, the presence of water, smoothness or roughness of the substrate, slope gradient, external actions (such as undermining at the foot or cutting of the covering) and, finally, anthropic action. Obviously, while leaving students free to experiment, it was necessary to give them a precise Driving Question.

\section{The Choice of Driving Questions}

Various Driving Questions were tested, with reference to the theoretical principles of formulation, in relation to the effectiveness of the stimulus that came from them and to the clarity of the chosen path's direction. 
Abstract, conceptual: such questions are answered to through logical discussion and conceptual analysis. There is no set answer, which makes them uneasy to answer to in one word. Students will have to justify their answers to these abstract and conceptual questions through a variety of activities.

Starting from a 3D representation (Figure 2):

- Which parts can you recognize in a landslide's slope and in its collapsed material?

- Which factors may trigger a landslide and accelerate its movement?

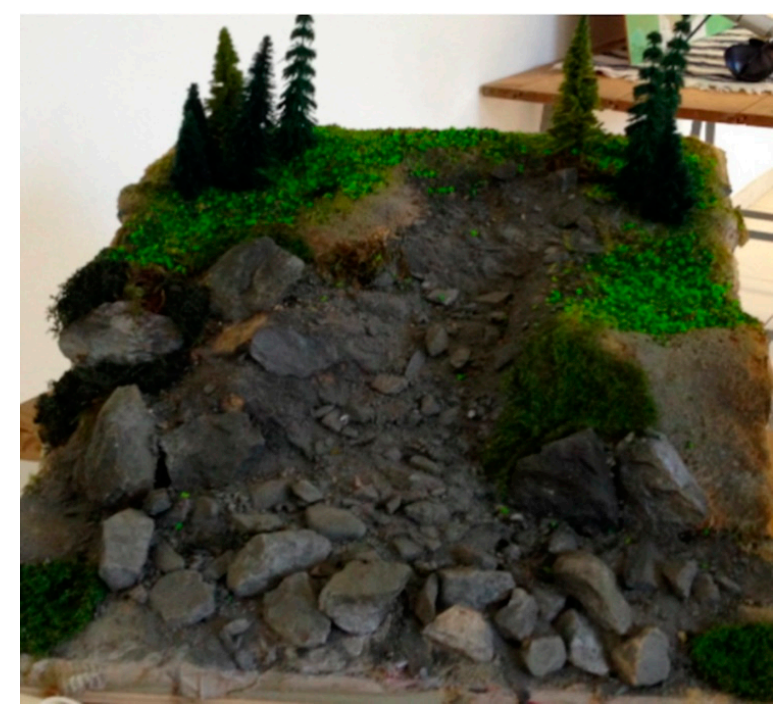

Figure 2. A 3D model of a landslide.

The answer must derive from experimentation, although in some cases (although not frequently) they may seem obvious.

Examples of simulation of landslides (Figure 3) made using different:

- materials;

- humidity;

- slopes;

- roughness of substrate;

- human actions.
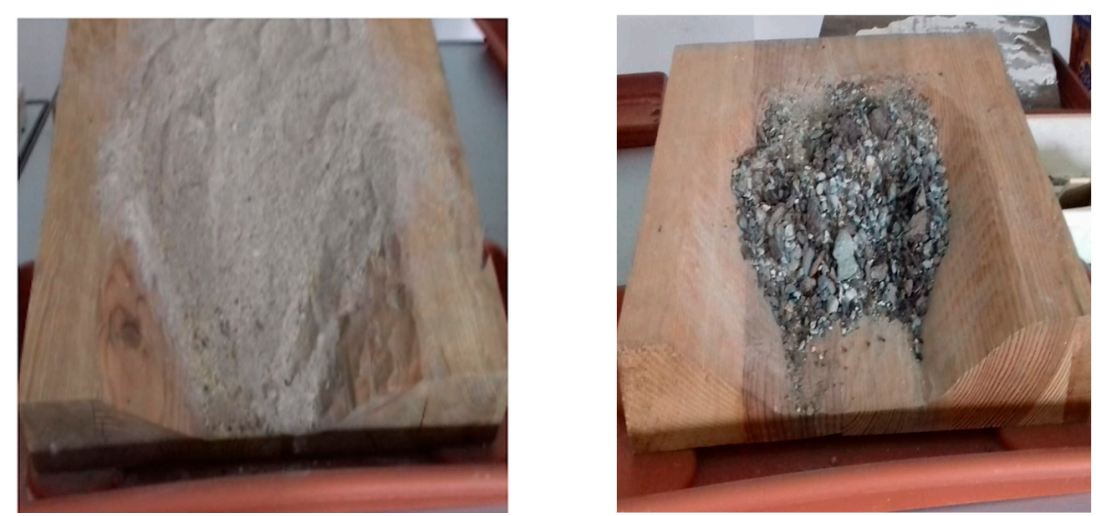

Figure 3. Preparation of a landslide model with different materials (sand or gravel).

Then, the Driving Question can be: 
Concrete: to be answered to, this type of question requires analysis of empirical evidence. Students must carry out research to prove the correctness of their answers. In this case, there is a set answer, but with several ways to obtain it:

- Why do some materials break down more easily than others?

Students discovered that poorly cohesive materials (or snow) do not necessarily "fall apart" more easily as the slope gradient increases: after a certain value (a $50^{\circ}$ gradient was tested), materials do not "stand up", and snow does not settle (Figure 4).
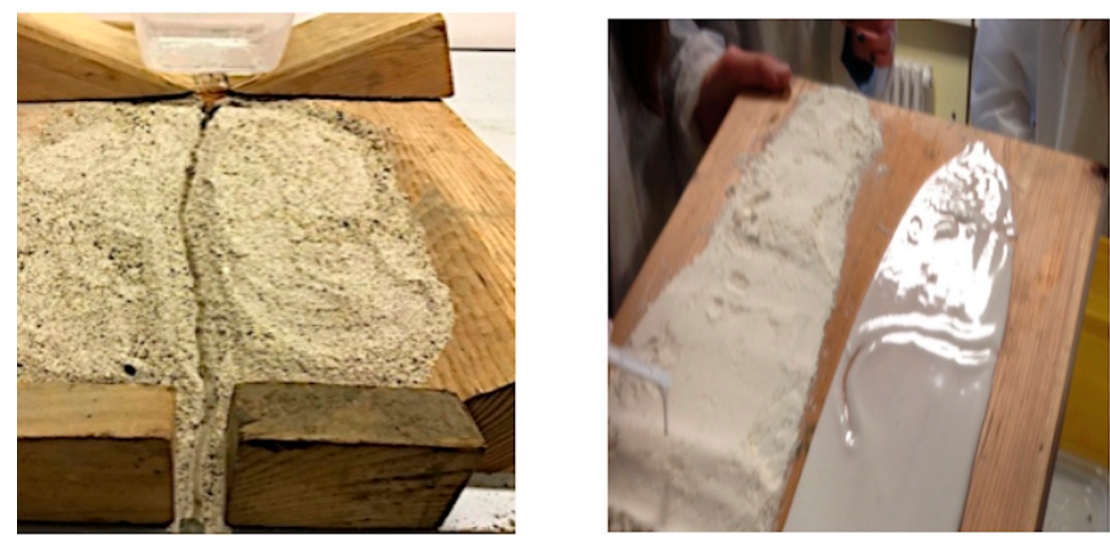

Figure 4. Models of different phenomena (erosion or avalanche).

Problem Solving: this type of question is answered to by providing reasonable solutions. Students must work together to generate them.

- Is it possible to make an area which is subject to landslides safe?

Design Challenge: such questions can be answered to by creating and implementing design models that effectively meet the questions' requirements.

- $\quad$ Find the solutions through which you can improve security conditions in the area.

\section{The Focus on Reality}

Having verified that the traditional transmissive approach seems, in general, to have low educational effectiveness and does not increase students' awareness of the issue of natural dangers and risks, it was decided to contextualize the learning process. This was done by making a deep experience on a sufficiently known environment, which was chosen depending on the presence of the following factors:

- a known and significant geological context, with tectonic contacts and clear geological units, well inserted in the dynamics of plate tectonics and orogenesis (in this case, the Alpine orogeny);

- an easily recognizable geomorphological evolution, with evident phenomena, identifiable both on the ground and on maps;

- interaction with anthropized and urbanized territories.

In this case, it was not essential that students knew the territory's basic elements, its geomorphological evolution and a landslide's triggering factors, whatever the type: the transition from simulation with models to reality was immediate.

By observing and comparing images, topography, thematic maps, 3D images (taken from Google Earth) or photogrammetric images, students analyzed the same variables as before: the materials, slopes and triggering factors, including anthropic action. 


\section{The Choice of Location}

One of Aosta Valley's side valleys was positively identified thanks to the presence of the aforementioned factors, which allowed the experimentation to be correctly focused on tools, methodological approaches and the analysis of outcomes. Three examples of three types of landslide are proposed:

- a slump;

- a deep earthflow (in Italian, DGPV);

- a deep debris flow.

\section{The Chosen Location}

The Valtournenche is a side valley on the left of the Dora Baltea Valley, in Aosta Valley, an Italian region on the country's north-western border. This side valley is characterized by the presence of the Matterhorn or Mount Cervino at its north: an area of great natural value, due to the landscape's beauty, the mountains, the lakes and the presence of skiing areas of high sporting interest, with significant tourist numbers and therefore consistent human settlements on its entire territory (Figure 5).
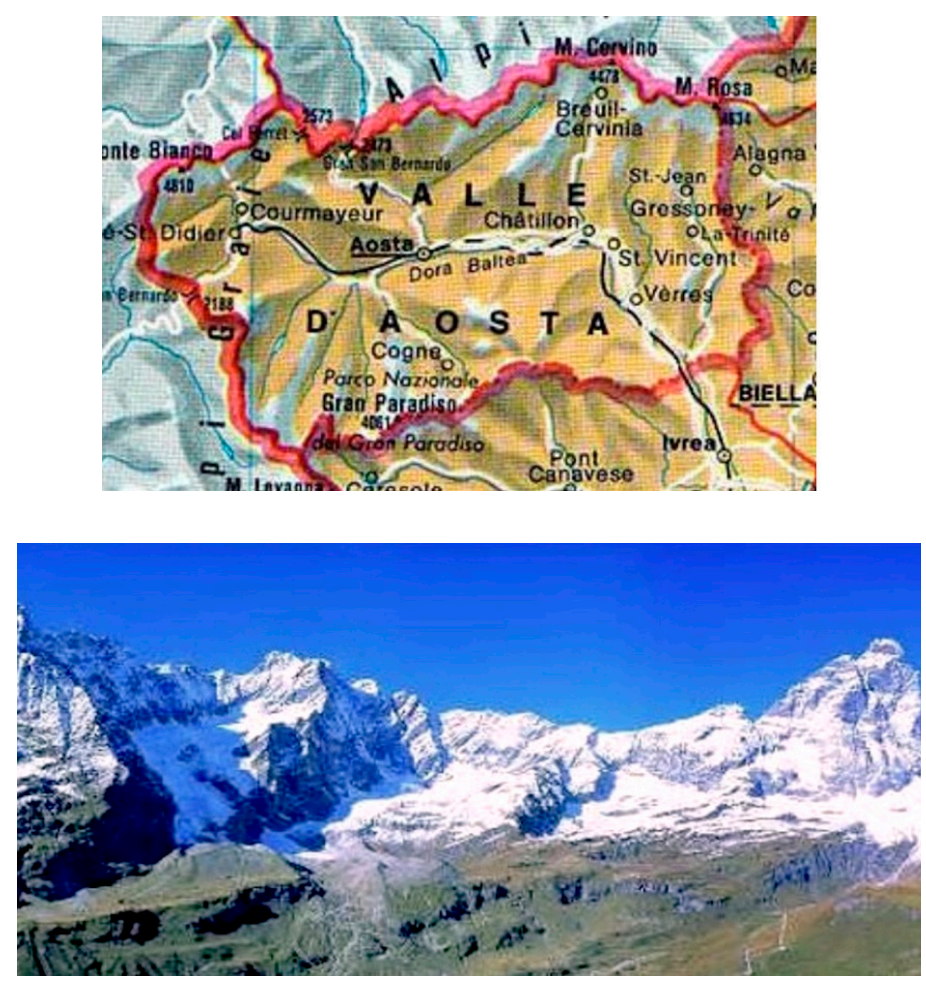

Figure 5. The Valtournenche Valley with the Matterhorn (or Mount Cervino) in the background.

\section{An Outline of The Valley's Geology}

The Valtournenche presents an exceptional geological nature [7,8]. Its main floor corresponds approximately to the point of contact between the African and European plates, in their slow motion closing and raising the Tethys, the ocean anciently separating them. The ocean's basin, recognizable in the characteristic green rocks, the ophiolites, which are abundant here, was raised to over 3000 meters of altitude, dragging with it coral islands, whose materials are now irregularly diffused: it is possible to recognize them in the three white teeth, the Cime Bianche, and in the white strip that runs along the left orographic side of the valley.

More in detail, several rocky bodies align along the valley, with mineral associations of the greatest interest for understanding Alpine dynamics and landscape. 
The Valtournenche is located approximately at the top of the rock complex named Sesia-Lanzo. During the first phase of Alpine orogenesis these rocks were torn from the edge of the African plate and quickly dragged into terrestrial lithosphere down to the depth of 50-60 kilometers, where they underwent transformations in conditions of very high pressure and relatively low temperature. This resulted in the formation of eclogite, essentially consisting of pyroxene sodium, omphacite and garnet, disposed in roundish red crystals.

This same geological unit expanded just to cover, at the top of the Alpine building, most of the region's territory. Now, erosion has separated a large part of the African blanket from its roots (the Sesia-Lanzo massif), forming isolated sections such as the klippen (which takes its name from the Swiss Dent Blanche massif), that constitutes the right orographic side of the high Valtournenche unit. A clear morphological contrast, highlighted by the Grandes and Petites Murailles' crest and by the Matterhorn's pyramid, is recognizable, marking the appearance of the large African continental crust fragment of the Dent Blanche.

The left side of the valley is made of rocks of the deep oceanic unit named Zermatt-Saas, consisting of three elongated elements disposed along the valley's axis: an ancient lithospheric mantle (serpentinites), ancient basaltic magmas derived from it, metabasites and a subtle level of ancient oceanic sediments, now micaschists.

\section{First Example: A Slump}

The first and clearest example, on the valley's middle right side, is given by still clearly visible slumps that occurred in the 1980s (Figure 6).
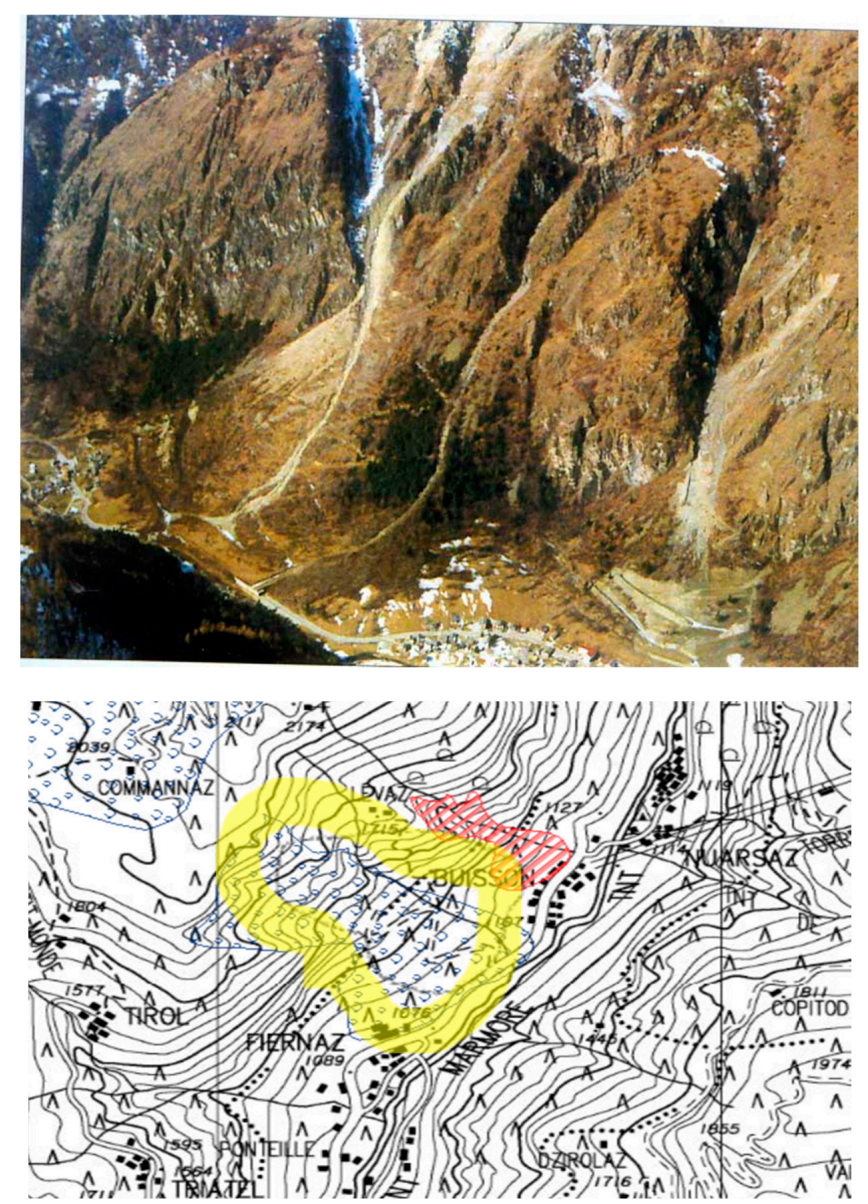

Figure 6. The Fiernaz slope: in yellow, its perimeter as identified by students. 
The collapse affected a very steep slope, of rock and superficial debris, more than 800 meters high, in very compact rocks scarcely concerned by the glacier's erosion that shaped the valley during the last glaciation.

Students were able to recognize in photographs the different parts of the phenomenon: the detachment sector, the accumulation of detritus and the affected area, including the inhabited area below. They were also able to identify it in cartography, even if its limited extension did not significantly change the territory's shape [9].

The Driving Question was: Students were asked to propose hypotheses on the phenomenon's causes. Many interesting hypotheses were formulated: the slope's steepness, the rocks' quality, the action of a small internal river, heavy rain. However, the most probable cause (which was shown only later) was a deep fault that affected the slope throughout its central sector, and perhaps water leaking from the upstream morphological terrace.

Finally, we asked pupils to try to delimit the areas certainly or potentially affected by the phenomenon, and therefore the consequent risk. It is interesting to note that they overestimated the potentially concerned area, which covered the entire inhabited center.

They were able to formulate important considerations on the village's vulnerability and risk, as hypotheses of passive interventions, protection and active debris of the slope.

\section{Second Example: A Deep Earthflow (DGPV)}

The second case is far more complex and particularly impacting, because of its location: a very famous touristic area at the Matterhorn's foot.

The phenomenon concerns the left side of the valley's top, where the southern part of the town of Cervinia is: movement affects the entire slope, from the watershed crest (which is therefore typically duplicated) up to the valley's floor (widely affected by slope breaks, steep slopes, rock glaciers with typical displacement wrinkles and irregular springs). Deformation is articulated in important structures oriented on the north-south axis: these structures separate sectors with different degrees of evolution and at different speeds [10].

In the downstream sector (the one mostly affected by high pressure) there are some touristic complexes, whose construction required the use of important engineering solutions to guarantee the buildings' (such as tower foundations reaching 30 meters of depth) stability.

By carefully observing aerial photos or Google Earth, it was possible to recognize the crest's duplication, the slope breaks and some of the glaciers' typical slippery wrinkles: students were asked to mark the most evident ones.

Furthermore, in this case they were asked to carry out an analysis of dangers and an assessment of vulnerability, finally obtaining an evaluation of risk which proved to be very high, due to the presence of touristic and hotel structures (Figure 7).

The analysis required very lively in-depth discussion, because the perimeter of the surface to be delimited was highly extensive, covering the entire slope for more than 1000 meters of altitude: above all, this delimitation interfered with important economic interests. Eventually, the perimeter delimited by students was compared with that defined in technical studies with interesting results. 

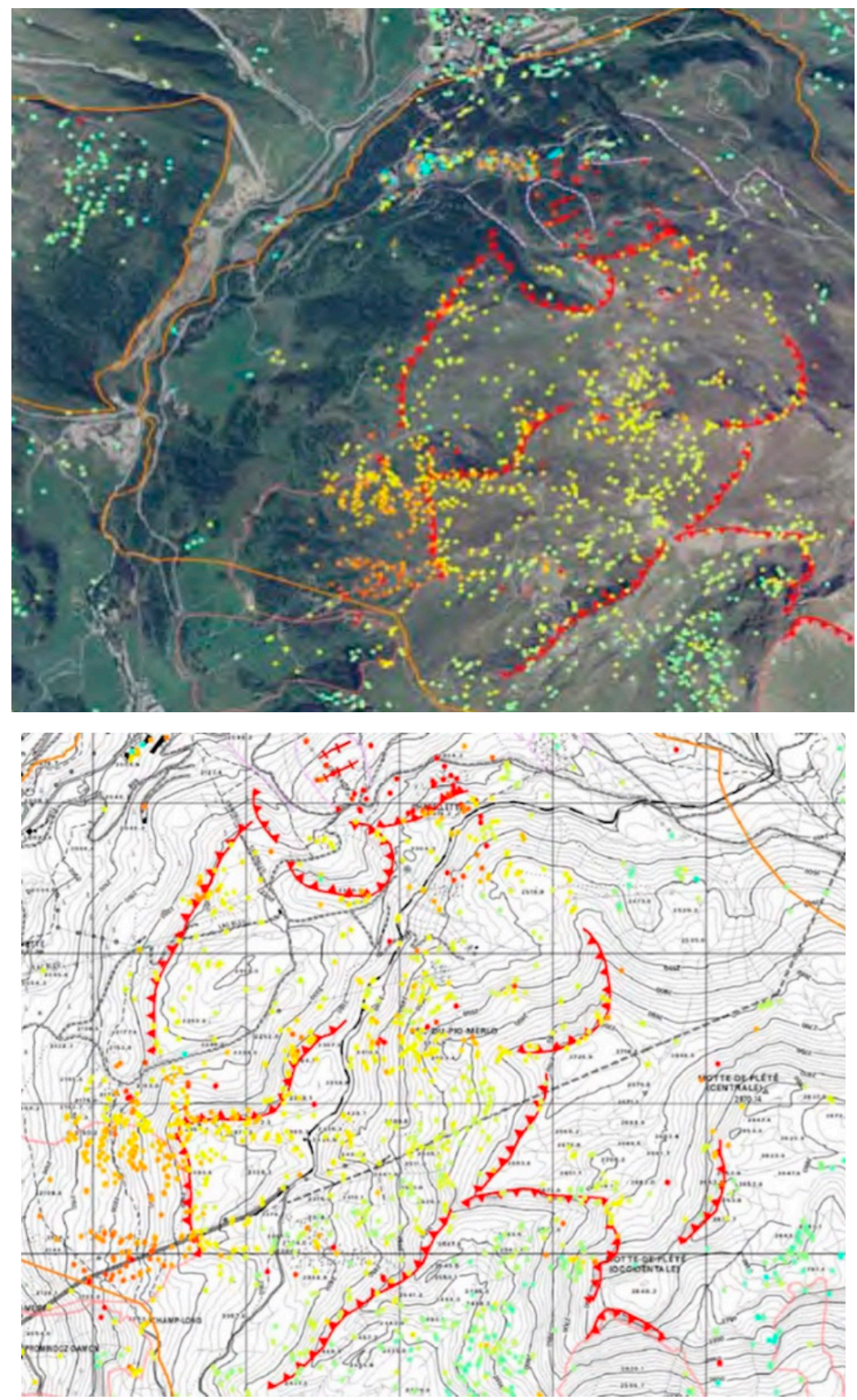

Figure 7. The deep earthflow in Cervinia.

\section{Third Example: A Deep Debris Flow}

The third and most difficult example is the less recognizable, but also the one with the greatest consequences on the area's morphology, since it affects the valley's east side, in its initial part concerning the village of Torgnon (Figure 8).

It is a slip undermining the entire slope, articulated in a series of broad transverse steps that subdivide the affected area into three distinct sectors, with landslide accumulations in the lowest one. The highly anthropized morphological terraces, with several inhabited centers and high touristic impact (because of the presence of skiing facilities and hotels), were interested in the post-glacial age by a deep flow, presumably in several inhomogeneous blocks stretching for over 1000 meters of altitude up to the valley's floor $[10,11]$. 
The landslide's body blocked the valley and formed a dam that produced a lake basin, currently filled by a paleo-riverbed's plain. In its terminal part, towards the mountain, there still are wet areas that in local toponymy are called lillaz ("the island"). Students were asked to recognize the area affected by movement, which turned out to be bounded by streams flowing at the landslide's sides. The watershed's curved trend, that was observed and shared, made the recognition relatively simple.
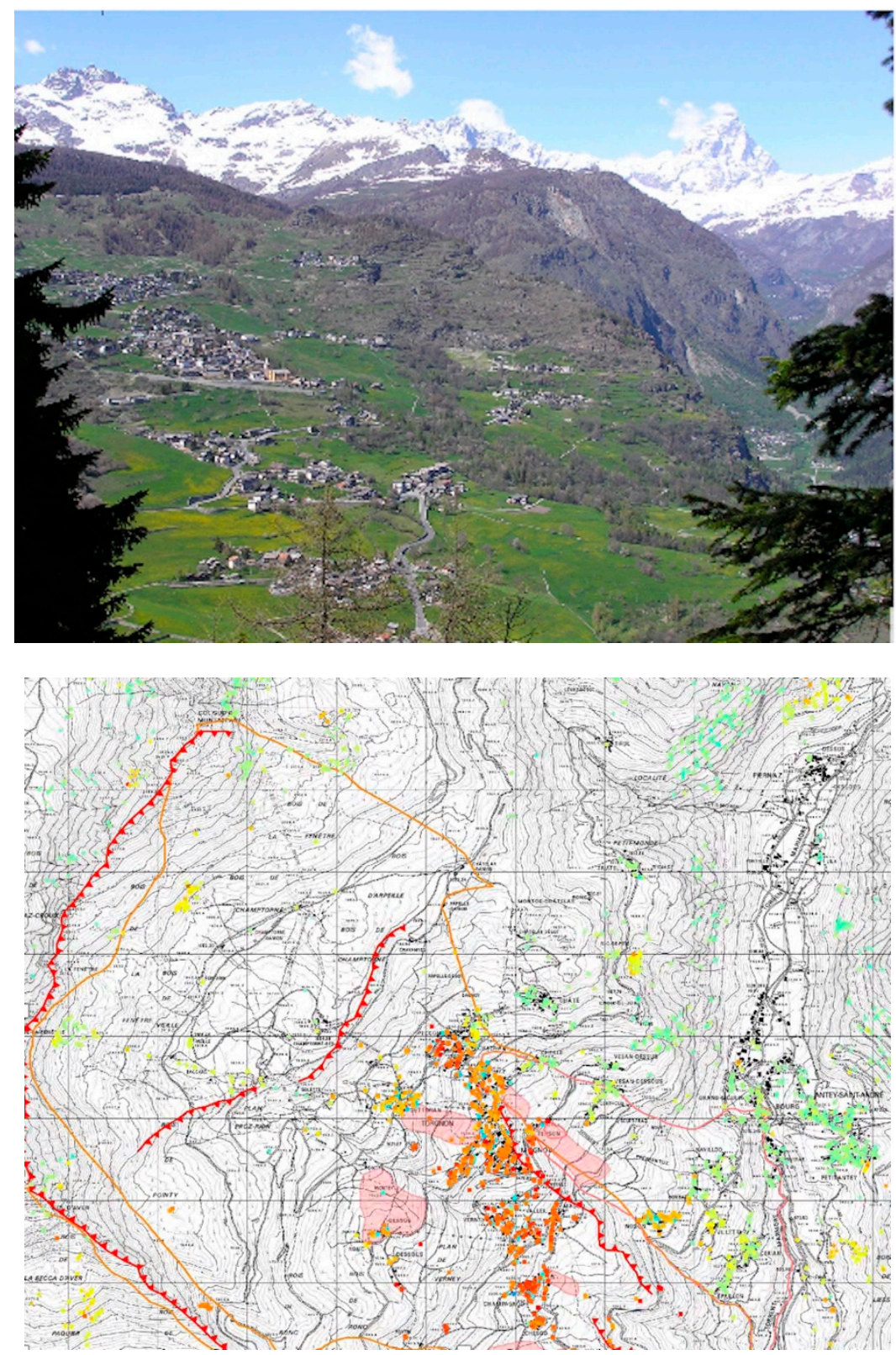

Figure 8. The deep debris flow in Torgnon.

However, students were surprised by the phenomenon's extension: superficially, it shows no instability in slopes, nor slope breaks in the versant's profile or instability in constructions.

But the water's particular outflow and the frequent presence of wetlands (consequent to the missing or irregular drainage of underground waters) were rightly pointed out.

Students tried to identify potentially endangered areas (with some difficulty due to the phenomenon's exhaustion) and vulnerable areas: in the second case, they underestimated the areas to be circumscribed.

Finally, the historical peculiarity of an ancient irrigation canal (common in an area characterized by low annual rainfall) was observed. In the contact points between rocky outcrops and the landslide's 
body, the canal was regularly interrupted by the soil's limited but evidently uninterrupted movement: as a matter of fact, it was called $R u d u$ Pan Perd $u$ (Fr.), which means "wasted bread canal", representing ineffective work (Figure 9).

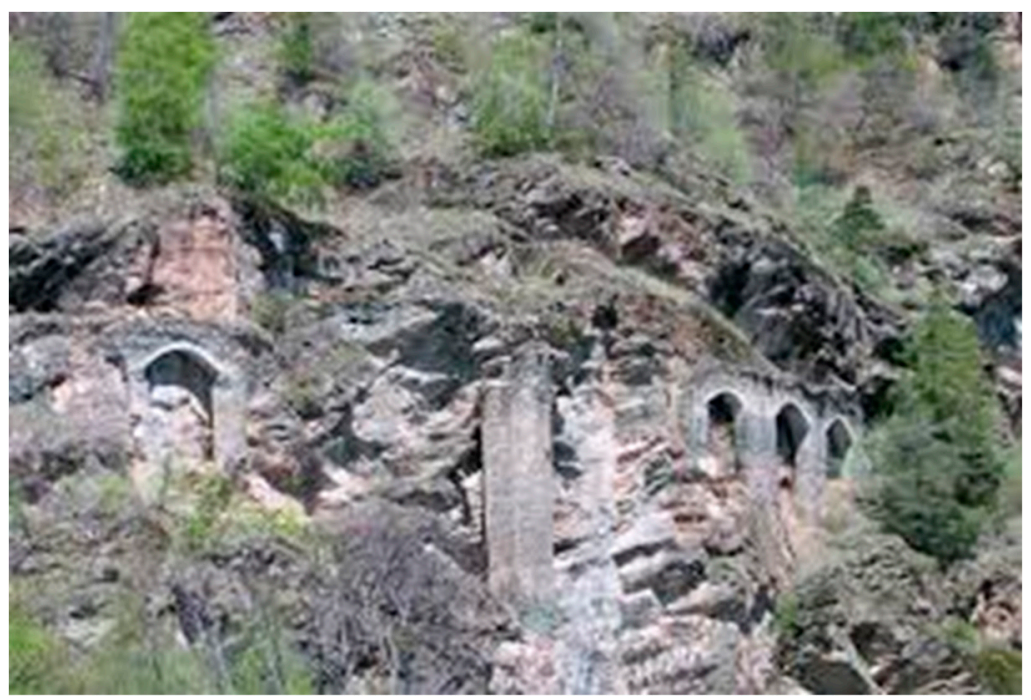

Figure 9. The Pan Perdu Ru: the "wasted bread canal".

\section{Discussion}

The entire activity was carried out in groups, mainly to allow the subsequent comparison and in-depth discussion on it, but also for reasons of time. During it, the following necessary Driving Questions were posed:

- Is it possible to recognize, in photography or cartography, elements or shapes of the landscape that allow the identification of a landslide, a collapse, a deep slide?

- Is it possible to recognize and characterize the type of danger, and the factors that may have triggered or reactivated it?

- What information is necessary to correctly define the area's vulnerability?

- How can we cross-refer information coming from geological-geomorphological analysis, that allows to highlight dangers and the anthropic-urban planning determining an area's vulnerability, in order to detect risk?

To verify if the training path produced real understanding of phenomena, the students faced a new geological event, currently stabilized, with familiar types and dynamics, but of course different consequences.

In this case, however, they were invited to perform a backward analysis.

Backward analysis is often used in the study of real events, in presence of which it may be difficult to apply scientific rules and laws: in an event such as an earthquake, a landslide or an avalanche, vulnerability factors can be determined, dangers can be put into models, but the phenomenon itself can hardly be formalized by scientific laws. Since the fact could not be analyzed through theoretical models, it was proposed to students to play the footage on it backwards, considering all its possible triggering factors and reconstructing the different dynamics that might have caused it. Inevitably, analysis started at the end, after the event had occurred, as too often happens. More appropriately, a phenomenon's occurrence should be analyzed by studying a priori the intervening dynamics and triggering factors, in order to prevent them.

It was interesting to try leading back all landslides and flows affecting the valley to some common factors: the rocks' type, the diffused and very thick local debris, the glacier's decisive action (which filled the valley with layers hundreds of meters thick and determined, on its withdrawal -especially in 
correspondence of morphological curves or discontinuity of substrate- the collapse or pouring of the entire slope).

\section{Conclusions}

Since the present educational path is operational and still experimental, it was not easy to identify tools and elements to be assessed and evaluated.

Students were observed in their groups, their responses were considered and formalized, the discussions' outcome was compared and transformed into graphic tools or schemes. The most effective evaluation was on the students' ability to recognize phenomena, causes and dynamics and to apply this knowledge to similar, but nevertheless different contexts.

Their ability to work in groups, to communicate effectively and to link causes and effects was also considered.

What I found particularly interesting and useful is that these evaluation areas are strictly related to the European Key Competences for Lifelong Learning (Recommendation 2006/962/EC of the European Parliament and of the 18th December 2006 Council on Key Competences for Lifelong Learning) [12]. Such competences are all interdependent, and commonly focused on critical thought, creativity, spirit of initiative, problem solving skills, risk assessment and decision taking skills. Among the eight key competences, some are particularly consistent with those developed during the activities, subsequently reported in abstract with essential knowledge, skills and attitudes relating to each of them:

- learning to learn is related to learning and to the ability to pursue and organize autonomous learning, either individually or in groups;

- $\quad$ social and civic competences refer to personal, interpersonal and intercultural competences that allow individuals to participate effectively and constructively in social and working life;

- $\quad$ spirit of initiative and entrepreneurship is the ability to transform ideas into action, which involves creativity, innovation and taking risks, as well as the ability to plan and manage projects in order to achieve objectives $[12,13]$.

In conclusion, it is not surprising, but it is nevertheless critical, that students (and society as a whole) are not highly aware of natural hazards that affect us, with devastating effects: as if, by refusing their existence, acting like the ostrich hiding its head, real dangers can be denied. However, not recognizing dangers leads inevitably to the lack of knowledge and prevention, and therefore to catastrophes and serious damage.

These activities, which tested an educational approach and a different way of addressing the issue and verifying the acquisition of knowledge and skills, obtained the double result of raising the awareness of environmental dynamics and risks and determining the growth of technical skills, such as knowing how to observe or recognize relationships, and of citizenship competences.

Funding: This research received no external funding.

Conflicts of Interest: The author declares no conflict of interest.

\section{References}

1. Gravina, T.; Greco, R.; Boccardi, V.; Cossu, C.; Piccioni, E.; Occhipinti, S. Could participation in a Science Olympiad engage students in studying Earth Science? The results from the participants in Italian Earth Science Olympiads. In Proceedings of the 8th Quadrennial Conference of the International Geoscience Education Organization, Campinas, Brazil, 27-28 July 2018.

2. Occhipinti, S. Models and Guidelines for More Effective Tools and Paths in an Active Teaching-Learning in Earth Sciences: Looking for a Unifying Principle. Ph.D. Thesis, Unicam University, Camerino, Italy, 2014.

3. Occhipinti, S. Invited Talk Promoting Earth Sciences' Teaching-Learning in Italian Schools: The Need of a Great Professionalism, of Effective Educational Approaches and of Extensive Cooperation, 2016. Available online: https://www.socgeol.it/307n170/88-congresso-nazionale-della-societa-geologica-italiana-geoscienceson-a-changing-planet-learning-from-the-past-exploring-the-future.html (accessed on 11 April 2019). 
4. Occhipinti, S. Promoting Earth sciences teaching-learning in the Italian schools: Improving students' skills and competence, diffusing new effective educational approaches, extending cooperation and networking. Rend. Online Della Soc. Geol. Ital. 2018, 4-10. [CrossRef]

5. Occhipinti, S.; Piccioni, E.; Lancellotti, L. The Teaching-Learning of Earth Science in Italy in Earth Science Education-Global Perspectives GRECO R. AMBERG, 2018. Available online: http://www.igeoscied.org/ teaching-resources/geoscience-text-books/ (accessed on 11 April 2019).

6. Thomas, J.W. A Review of Research on Project-Based Learning, 2000. Available online: https://www.asec. purdue.edu/lct/HBCU/documents/AReviewofResearchofProject-BasedLearning.pdf (accessed on 25 March 2019).

7. Dal Piaz, G.V.; Pennacchioni, G.; Tartarotti, P.; Carraro, F.; Gianotti, F.; Monopoli, B.; Schiavo, A. Carta Geologica D'Italia Alla Scala 1:50,000, Foglio 091 Chatillon; Istituto Superiore per la Protezione e la Ricerca Ambientale: Ispra, Italy, 2010.

8. Servizio Geologico D'italia-2017 Memorie Descrittive della carta geologica d'Italia vol.101 Note Illustrative del F. 070 Monte Cervino della carta Geologica d'Italia alla Scala 1:50,000. Available online: http://www.isprambiente.gov.it/files2017/pubblicazioni/periodici-tecnici/memorie-descrittive-dellacarta-geologicaditalia/volume101/memdes_101_caratteri_geografici_e_geomorfologici.pdf (accessed on 10 April 2019).

9. Regione Valle d'Aosta, Servizio Geologico-2012. Available online: http://www.risknet-alcotra.org/rna/ allegati/risknat-b2-c2-schede-frane-vda_1023.pdf (accessed on 11 April 2019).

10. Sara Ratto (Regione Autonoma Valle d'Aosta), 2007. Available online: http://www.isprambiente.gov.it/files/ pubblicazioni/rapporti/rapporto-frane-2007/Capitolo_6_Valle_Aosta.pd (accessed on 11 April 2019).

11. IFFI-Inventario dei Fenomeni Franosi in Italia-Italiano-Ispra. Available online: http://www.isprambiente.gov. it/it/progetti/suolo-e-territorio-1/iffi-inventario-dei-fenomeni-franosi-in-italia (accessed on 12 April 2019).

12. European Parliament. Recommendation 2006/962/EC of the European Parliament and of the Council of 18 December 2006 on Key Competences for Lifelong Learning. Available online: https://eur-lex.europa.eu/ LexUriServ/LexUriServ.do?uri=OJ:L:2006:394:0010:0018:en:PDF (accessed on 23 March 2019).

13. Pisa OECD-2015 Result on Focus-Sciences. Available online: https://www.oecd.org/pisa/pisa-2015-resultsin-focus.pdf (accessed on 25 March 2019).

(C) 2019 by the author. Licensee MDPI, Basel, Switzerland. This article is an open access article distributed under the terms and conditions of the Creative Commons Attribution (CC BY) license (http://creativecommons.org/licenses/by/4.0/). 